\title{
Effect of Deep Cryogenic Treatment on Electrical Conductivity of Cu-Base Multicomponent Alloy
}

\author{
Shuqing Chen ${ }^{1}$, Jimeng $\mathrm{Li}^{2}$ and Xiaojie Zhao ${ }^{2}$ \\ 1. College of Science, Yanshan University, Qinhuangdao 066004, China \\ 2. College of Materials Science and Engineering, Yanshan University, Qinhuangdao 066004, China
}

Received: December 03, 2013 / Accepted: December 20, 2013 / Published: February 25, 2014.

\begin{abstract}
The electrical conductivity of Cu-base multicomponent alloy before and after deep cryogenic treatment at different situations were measured by conductance instrument, its microstructures were also characterized by optical microscope, and the effect of deep cryogenic treatment on the electrical conductivity of $\mathrm{Cu}$-base multicomponent alloy was studied in this paper. The results show that deep cryogenic treatment can change the electrical conductivity of $\mathrm{Cu}$-base multicomponent alloy, and the electrical conductivity increases with the extension of deep cryogenic treatment time, when deep cryogenic treatment time exceeded 100 min, electrical conductivity increases slightly. However, the higher electrical conductivity can be obtained by aging at $500{ }^{\circ} \mathrm{C}$ for $30 \mathrm{~min}$ after deep cryogenic treatment.
\end{abstract}

Key words: Cu-base multicomponent alloy, deep cryogenic treatment, electrical conductivity.

\section{Introduction}

Due to excellent properties in strength, thermal conductivity and electrical conductivity, $\mathrm{Cu}$ alloy is widely applied in various fields such as integrated circuit frame, Welding electrodes, and switch contacts of Electrical engineering [1-4]. With the rapid development of technology and modern industry, $\mathrm{Cu}$ alloy with higher properties are required. The main methods to improve the performance of $\mathrm{Cu}$ alloy are adding alloying elements, improving manufacturing technique, and performing subsequent heat treatment [5-7]. Deep cryogenic treatment, which is a new method applied to metal materials, is helpful to improving properties [8-11]. However, the effects of deep cryogenic treatment on electric conductivity of $\mathrm{Cu}$-base alloy rarely appear to have been researched previously in studies reported in the literature. In this paper, therefore, the influence of deep cryogenic

Corresponding author: Shuqing Chen, Master, senior engineer, research field: metallic materials. E-mail:csqing326@yahoo.com.cn. treatment on the electrical conductivity of a new $\mathrm{Cu}$-base multicomponent alloy was studied, which provides experiment foundation on improving electrical conductivity of the alloy.

\section{Experiments}

The experimental material was as-cast $\mathrm{Cu}$-base multicomponent alloy, and the composition (mass fraction, \%) is $97.89 \mathrm{Cu}, 0.82 \mathrm{Se}, 0.71 \mathrm{Te}, 0.41 \mathrm{Al}$, $0.17 \mathrm{Cr}$. The casting blank were cut into $\Phi 10 \mathrm{~mm} \times 5$ $\mathrm{mm}$ size specimens which were heated to $850{ }^{\circ} \mathrm{C}$ in box resistance furnace for $30 \mathrm{~min}$. Then the samples were immersed in liquid nitrogen $\left(-196{ }^{\circ} \mathrm{C}\right)$ immediately, and keep them in liquid nitrogen for $20,40,60,80,100,120,140$ and $160 \mathrm{~min}$, respectively. After that, the samples were treated with aging held at different temperature through different time. A WD-Z-type eddy conductance instrument was used to measure the electrical conductivity of the $\mathrm{Cu}$ alloy. The microstructure of samples was analyzed by Axiovert200MAT metallographic microscope. 


\section{Results and Discussion}

\subsection{Microstructure}

Fig. 1 shows the microstructure of the $\mathrm{Cu}$-base multicomponent alloy before and after deep cryogenic treatment. It can be seen that the microstructure is composed of $\mathrm{Cu}$ matrix and irregular particles which were distributed in the $\mathrm{Cu}$ matrix, the irregular particles were compounds of $\mathrm{Cu}$ and $\mathrm{Se}(\mathrm{Te})$. The microstructure of the $\mathrm{Cu}$ alloy is slightly refined after deep cryogenic treatment.

\subsection{Conductivity}

Fig. 2 shows the changing curves between electrical conductivity of the $\mathrm{Cu}$-base multicomponent alloy and the treating time of deep cryogenic treatment. It can be seen that the conductivity reduces from $52.35 \%$ IACS before the deep cryogenic treatment to $53.17 \%$ IACS held at $850{ }^{\circ} \mathrm{C}$ for $20 \mathrm{~min}$ and immediately immersed in liquid nitrogen $\left(-196{ }^{\circ} \mathrm{C}\right)$ for $30 \mathrm{~min}$. The conductivity increases with the extension of time, but the conductivity increases slightly when the deep cryogenic treatment was over $100 \mathrm{~min}$.

The deep cryogenic treatment contains two stages, cooling and insulating at a low temperature. $\mathrm{Cu}$ alloy is cooled rapidly from $850{ }^{\circ} \mathrm{C}$ to liquid nitrogen temperature $\left(-196^{\circ} \mathrm{C}\right)$, which leads to the change of the microstructure. On the one hand, the solid solution atoms in the solidified $\mathrm{Cu}$ alloy matrix precipitated too late from $\mathrm{Cu}$ solid solution, lattice distortion in $\mathrm{Cu}$ solid solution is serious caused, on the other hand, the

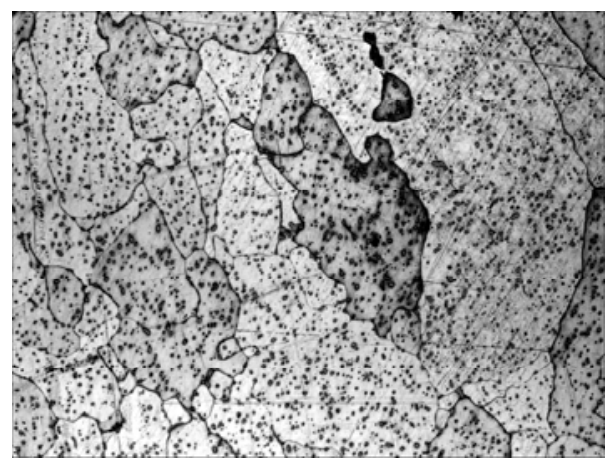

(a)
$\mathrm{Cu}$ lattice contraction due to the rapid changing of temperature, induced a greater internal stress and a large number of dislocations in the material. Besides, deep cryogenic treatment refines the microstructure and increases the number of grain boundaries. This leads to the strong electronic scattering, which result in reducing the conductivity. The solid solubility of solute atoms is low at the low temperature. When the $\mathrm{Cu}$ alloy was immersed in liquid nitrogen, the supersaturated atoms precipitated from $\mathrm{Cu}$ alloy matrix, and the amount of the precipitates in the matrix increases as time goes on. Although precipitates increases the scattering of free electrons, which lead to decreasing of electrical conductivity, the effect of precipitates on scattering is lower compare with solute atoms in $\mathrm{Cu}$ alloy. Furthermore, deep cryogenic treatment for a long time can decrease the density of vacancy defect [12], and reduce the scattering of free electrons induced by vacancy defect. Therefore, the electrical conductivity increases with the time of deep cryogenic treatment extended. It can be seen from the results that the conductivity of alloy after deep cryogenic treatment for $100 \mathrm{~min}$ is $58.13 \% \mathrm{IACS}$, it has been increased by $8.53 \%$ compared with the conductivity of alloy before deep cryogenic treatment.

Fig. 3 shows relation curve between electric conductivity and temperature for the Cu-base multicomponent Alloy by deep cryogenic treatment for 100 min. It can be seen that the alloy electric conductivity increases and then decreases with the aging temperature increasing. The reason is that when

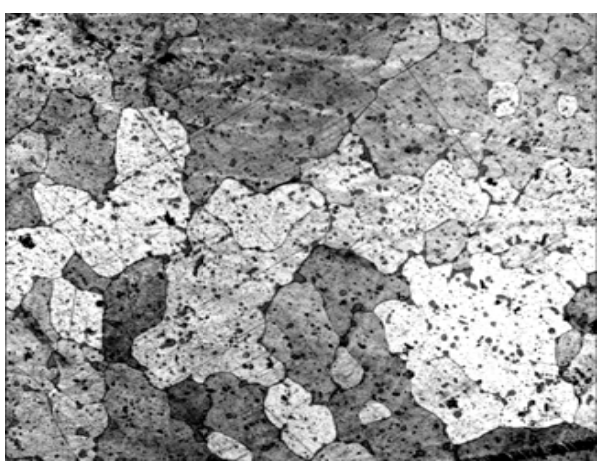

(b)

Fig. 1 Microstructure of $\mathrm{Cu}$ alloy before and after cryogenic treatment. (a) original and (b) cryogenic treatment (for 100 min). 


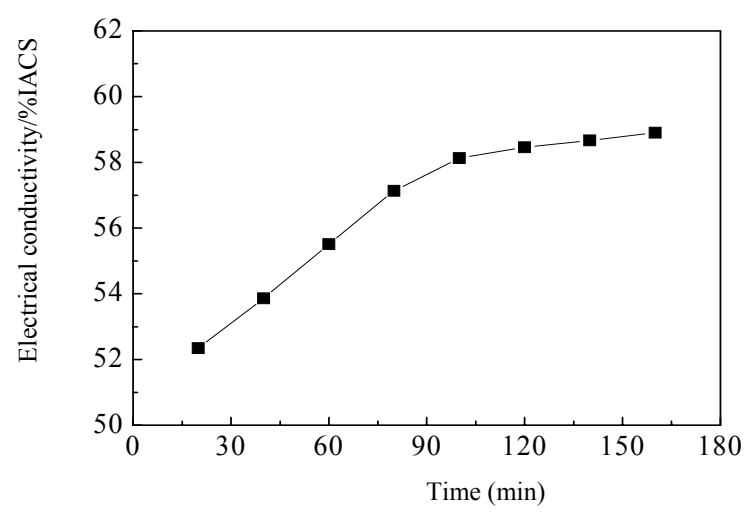

Fig. 2 Relationship between electrical conductivity of Cualloy and deep cryogenic treatment time.

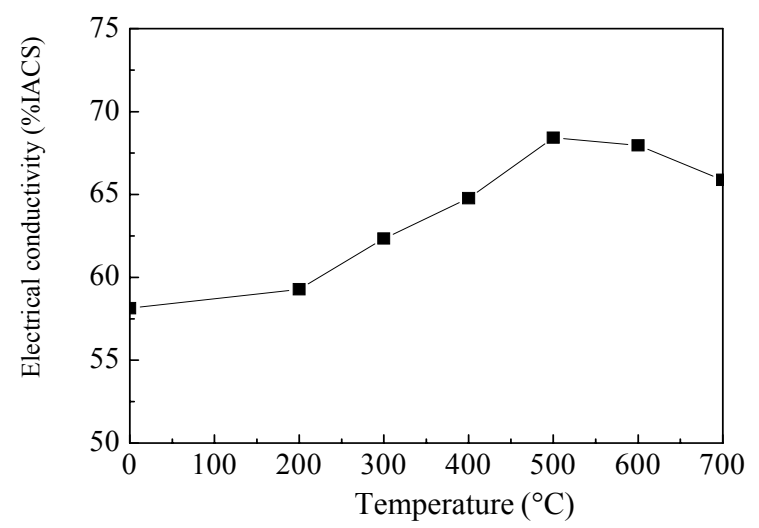

Fig. 3 Relationship between electrical conductivity of $\mathrm{Cu}$ alloy after cryogenic treatment and aging temperature for $30 \mathrm{~min}$.

the aging temperature is low, atomic diffusivity is weak, and the precipitates rate is slow, when the aging temperature is high, solid solubility of solute atoms in the $\mathrm{Cu}$ matrix increase and the saturation reduce, so the amount of the precipitated phase reduces. Thus the best temperature for electric conductivity is $500{ }^{\circ} \mathrm{C}$. Fig. 4 shows the relation curve between electric conductivity and time of Cu-base multicomponent Alloy treated by cryogenic for $100 \mathrm{~min}$. In the early time, the electric conductivity rise quickly with the aging time, when the aging time is $30 \mathrm{~min}$, the alloy electric conductivity rise from $53.17 \%$ to $68.42 \% \mathrm{IACS}$, increasing by $28.68 \%$ than that of the samples without deep cryogenic treatment. After aging over $30 \mathrm{~min}$, the electric conductivity increases a little.
At the early time of aging, the supersaturating is higher, the alloying element precipitate quickly with the form of second phase which making the electric conductivity increase quickly. The precipitated phase increase with the aging process, then the solute concentration of atoms gets balance, and the precipitate rate get slowly, so electric conductivity verge to stable. Noteworthy, the solubility of solute atoms reduce with the temperature decreasing. So after deep cryogenic treatment for a long time, Solute atomic precipitates thoroughly and the electric conductivity rises by a large margin. In fact, the electric conductivity of alloy after deep cryogenic treatment $\left(196{ }^{\circ} \mathrm{C}\right)$ for a long time is less than of the alloy treated by aging at $500{ }^{\circ} \mathrm{C}$ after deep cryogenic treatment. The reason is that at lower temperature, solute atoms have low solubility and high super saturation, but the diffusion of the solute atom is very difficult and migration length is short. Thus the precipitated phase become more diffused and the distance of precipitated phase is far less than that of the samples treated by aging at $500{ }^{\circ} \mathrm{C}$ after deep cryogenic treatment. The effect of precipitated phase on scattering of free electronic after deep cryogenic treatment is greater than that of aging at $500{ }^{\circ} \mathrm{C}$, which result in the lower electric conductivity of $\mathrm{Cu}$ alloy after deep cryogenic treatment than that of the alloy after aging at $500{ }^{\circ} \mathrm{C}$. Moreover, from Ref. [13]:

$\mathrm{Se}$ and $\mathrm{Te}$ element hardly soluble in $\mathrm{Cu}$, the solubility of $\mathrm{Al}$ are greater than its content at room

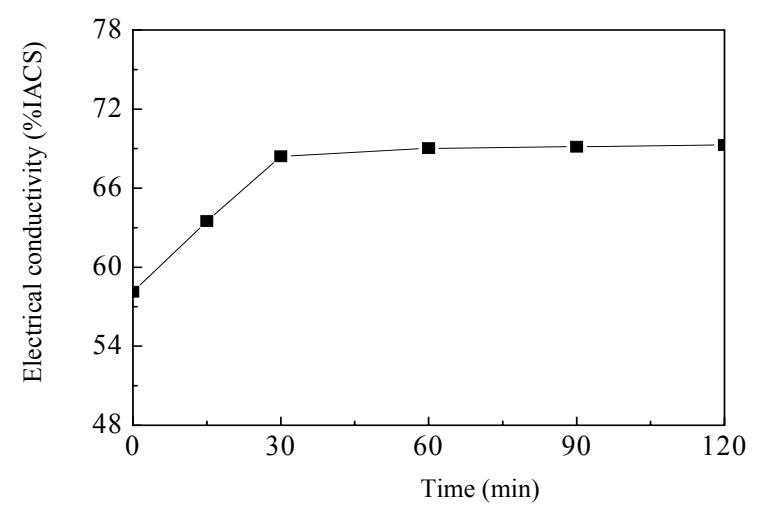

Fig. 4 Relationship between electrical conductivity of $\mathrm{Cu}$ alloy after cryogenic treatment and aging time (at $\left.500{ }^{\circ} \mathrm{C}\right)$. 
temperature, the solubility of $\mathrm{Cr}$ in the $\mathrm{Cu}$ less than $0.03 \%$. We can conclude that $\mathrm{Cr}$ is precipitated in $\mathrm{Cu}$ alloy during the deep cryogenic treatment process.

\section{Conclusions}

(1) Deep cryogenic treatment can improve the conductivity of the $\mathrm{Cu}$-base multicomponent alloy, the conductivity increases with the increase of deep cryogenic treatment time. The electrical conductivity of the $\mathrm{Cu}$-base multicomponent alloy treated by aging after deep cryogenic treatment is significantly increased;

(2) The higher electrical conductivity of the Cu-base multicomponent alloy is obtained by aging at $500{ }^{\circ} \mathrm{C}$ for $30 \mathrm{~min}$ after deep cryogenic treatment. The alloy electric conductivity is $68.42 \% \mathrm{IACS}$, increasing by $28.62 \%$ than that of the samples before deep cryogenic treatment.

\section{References}

[1] S.C. Krishna, J. Srinath, K. Jha, K. Abhay, P. Bhanu, S.C. Sharma, et al., Microstructure and properties of a high-strength $\mathrm{Cu}-\mathrm{Ni}-\mathrm{Si}-\mathrm{Co}-\mathrm{Zr}$ alloy, Journal of Materials Engineering and Performance 22 (7) (2013) 2115-2120.

[2] J.F. Wang, S.G. Jia, S.H. Chen, K.X. Song, P. Liu, G.J. $\mathrm{Yu}$, Effect of aging precipitation on properties of $\mathrm{Cu}-\mathrm{Ni}-\mathrm{Si}-\mathrm{Mg}$ alloy, Advanced Materials Research 197-198 (2011) 1315-1320.

[3] H.T. Zhou, J.W. Zhong, X.Z. Zhou, Z.K. Zhao, Q.B. Li, Effects of multi-step thermomechanical treatments on microstructure and properties of $\mathrm{Cu}-\mathrm{Cr}-\mathrm{Zr}$ alloy, Transactions of Materials and Heat Treatment 30 (3) (2009) 141-145.

[4] M. Kermajani, S. Raygan, K. Hanayi, H. Ghaffari, Production of $\mathrm{Cu}-\mathrm{Cr}-\mathrm{Zr}$ alloy using electroslag remelting technique, International Journal of Engineering, Transactions A: Basics 26 (7) (2013) 713-720.

[5] Z.Q. Cao, L. Yu, Y. Li, Y. Sun, Effect of Si addition on high temperature oxidation of $\mathrm{Cu}-20 \mathrm{Ni}-20 \mathrm{Cr}$ alloy, High Temperature Materials and Processes 29 (4) (2010) 295-303.

[6] S. Miyakawa, M. Nishida, N. Nishiyama, H. Miura, A. Inoue, Mechanical and electrical properties of rapidly solidified $\mathrm{Cu}-\mathrm{Zr}-\mathrm{Ag}$ alloy fabricated by powder rolling process, in: Materials Research Society Symposium Proceedings 1300 (2011) 68-73.

[7] Y.Z. Tian, S.D. Wu, Z.F. Zhang, R.B. Figueiredo, N. Gao, T.G. Langdon, Comparison of microstructures and mechanical properties of a $\mathrm{Cu}-\mathrm{Ag}$ alloy processed using different severe plastic deformation modes, Materials Science and Engineering A 528 (13-14) (2011) 4331-4336.

[8] M. Pellizzari, Influence of deep cryogenic treatment on heat treatment of steel and $\mathrm{Cu}-\mathrm{Be}$ alloy, International Heat Treatment and Surface Engineering 4 (3) (2010) 105-109.

[9] F. Cajner, V. Leskovsek, D. Landek, H. Cajner, Effect of deep-cryogenic treatment on high speed steel properties, Materials and Manufacturing Processes 24 (7-8) (2009) 743-746.

[10] V. Leskovšek, B. Ule, Cryogenic treatment influence of deep cryogenic treatment on microstructure, mechanical properties and dimensional changes of vacuum heat-treated high-speed steel, International Heat Treatment and Surface Engineering 2 (3-4) (2008) 155-161.

[11] D. Senthilkumar, I. Rajendran, Optimization of deep cryogenic treatment to reduce wear loss of 4140 steel, Materials and Manufacturing Processes 27 (5) (2012) 567-572.

[12] X.J. Chen, Z.Z. Yuan, J.S. Zhang. Influence of cryogenic treatment on electric properties of alloy $\mathrm{Cu} 15 \mathrm{Ni}-8 \mathrm{Sn}$, Journal of Gansu University of Technology 29 (2) (2003) 37-39.

[13] Z.T. Wang, Cu alloys and it's working handbook, Central South University Press, Changsha, 2002, p. 5. 